\title{
Correlation of Bacterial Sensitivities to Ionizing Radiation and Mild Heating
}

\author{
By B. A. BRIDGES, M. J. ASHWOOD-SMITH AND R. J. MUNSON \\ Medical Research Council, Radiobiological Research Unit, \\ Harwell, Didcot, Berkshire
}

\author{
(Accepted for publication I3 June I969)
}

\begin{abstract}
SUMMARY
DNA, isolated from bacteria which had been heated to $52^{\circ}$ for several minutes, sedimented in an alkaline sucrose gradient more rapidly than DNA from untreated bacteria, in a similar manner to DNA from bacteria exposed to ionizing radiation. There is a general correlation between the sensitivities to $\gamma$-radiation and to incubation at $52^{\circ}$ of various strains of Escherichia coli. Heated bacteria were more sensitive to subsequent exposure to $\gamma$-radiation, indicating that recovery capacity was itself heat-sensitive. The normal function of some of the cellular systems conferring radiation resistance might therefore be the mitigation of DNA damage due to mild thermal stress at elevated and perhaps also at normal temperatures.
\end{abstract}

\section{INTRODUCTION}

There is now a very considerable amount of evidence that the sensitivity of bacteria to radiation is under the control of distinct genes, many of which have been identified and mapped (see Adler (1966) for a review of the situation in Escherichia coli). It is also clear that most, if not all of these genes are concerned with the ability of the bacterium to recover from the radiation-induced damage, either by repairing damaged structures or by permitting the organisms to bypass or tolerate them (Haynes, 1964; Witkin, 1967; Moseley, 1968; Howard-Flanders, 1968).

Ionizing radiation is not found in natural environments at a value high enough to constitute a hazard to living organisms and there is thus speculation about the normal function of these recovery systems. One possibility is that they may be involved in normal metabolism, for example the process of genetic recombination (HowardFlanders \& Theriot, 1966). Alternatively they may counter the effect of other environmental hazards which produce damage not unlike that produced by ionizing radiation. The most common lesion known to be produced by ionizing radiation is breakage of one of the two strands of the bacterial DNA (Freifelder, 1965; McGrath \& Williams, 1966; Hagen \& Wellstein, 1965). Single strand breaks can also be produced by thermal stress. Spontaneous hydrolysis is known to be temperature dependent in the region between 80 and $100^{\circ}$ (Eigner, Boedtker \& Michaels, I96I). Depurination also occurs spontaneously at elevated temperatures (Greer \& Zamenhof, 1962) and apurinic sites might well be attacked by specific endonucleases (B.S. Strauss, personal communication). Moreover, endonucleases might be released into the cytoplasm by heat treatment.

The purpose of the experiments described here was to test the hypothesis that mild 
heating, at near-physiological temperatures, produces a type of damage similar to that produced by ionizing radiation. This hypothesis was suggested by the observation that single-strand DNA breaks are formed at near physiological temperatures. We have examined specifically the possibility that, at a temperature just above the maximum growth temperature, the rate of loss of viability of different strains might be determined largely by the presence of recovery systems and might therefore show a correlation with the sensitivity of the strains to ionizing radiation.

\section{METHODS}

Organisms. The Escherichia coli strains used, together with their sources and phenotypes with respect to radiation sensitivity, are given in Table I. For characterization of most of these phenotypes the reader is referred to Witkin (1967). Also used were Bacillus stearothermophilus strains and Micrococcus radiodurans.

Table I. Strains of Escherichia coli, their sources, and radiation sensitivity phenotypes

\begin{tabular}{|c|c|c|c|c|c|c|}
\hline \multirow[b]{2}{*}{ Strain } & \multirow[b]{2}{*}{ Parent } & \multicolumn{4}{|c|}{ Phenotype } & \multirow[b]{2}{*}{ Source } \\
\hline & & rec & exr & lon & her & \\
\hline $\mathrm{B} / \mathbf{r}$ & B & + & + & $\mathrm{Su}$ & + & Witkin \\
\hline $\mathbf{B}_{3} \mathbf{r}$ & (B) & + & + & $\mathrm{Su}$ & + & Alper \& Moore \\
\hline B & - & + & + & - & + & - \\
\hline$B_{8-1}$ & B & + & - & - & - & Hill \\
\hline $\mathrm{B}_{\mathrm{g}-2}$ & B & + & - & - & + & Hill \\
\hline WP 2 & $\mathbf{B} / \mathbf{r}$ & + & + & $\mathrm{Su}$ & + & Witkin \\
\hline WP 2 hcr $^{-}$ & WP 2 & + & + & $\mathrm{Su}$ & - & Hill \\
\hline IV -5 & $\left(B_{8-1}\right)$ & + & - & $\mathrm{Su}$ & - & Witkin \\
\hline$v-5$ & IV -5 & + & + & $\mathrm{Su}$ & - & Witkin \\
\hline $\mathrm{H} / \mathrm{r} 30-\mathrm{R}$ & (B) & + & + & $\mathrm{Su}$ & + & Kondo \\
\hline R 15 & $\mathrm{H} / \mathrm{r} \quad 30-\mathrm{R}$ & $-?$ & $-?$ & $\mathrm{Su}$ & + & Kondo \\
\hline NG 30 & $\mathrm{H} / \mathrm{r} 30-\mathrm{R}$ & - & + & $\mathrm{Su}$ & + & Kondo \\
\hline AB 1157 & . & + & + & + & + & Howard-Flanders \\
\hline$A B 2463$ & AB I I 57 & - & + & + & + & Howard-Flanders \\
\hline
\end{tabular}

Su indicates that the lon- phenotype is suppressed extragenically. This has been demonstrated for $\mathrm{B} / \mathrm{r}$ (Greenberg, personal communication) and is assumed to be so for other radiation-resistant derivatives of B. Parent strains in parentheses are more than one isolation step removed from their derivatives.

Cultural details. Exponential phase bacteria, grown at $37^{\circ}$ to about $1 \cdot 5 \times 10^{8} \mathrm{~cm} .^{-3}$, were used for all experiments, being heated or irradiated in their growth medium. Bacteria grown in glucose + salts medium (Haas \& Doudney, 1957) were diluted after treatment in salts medium without glucose and plated on to Oxoid Brain Heart Infusion solidified with $1.5 \%$ Difco Purified Agar at $37^{\circ}$. Bacteria grown in Oxoid Nutrient Broth no. 2 were diluted in $\mathrm{M} / 15$ phosphate buffer $(\mathrm{pH} 7)$ and plated on to the same medium solidified with I.5\% Difco Purified Agar. In some experiments plating was also done on glucose salts medium with I $5 \%$ Difco Purified Agar. Three independent dose-survival curves were obtained with each strain. Micrococcus radiodurans was grown in Oxoid Dextrose Peptone Broth and plated on Oxoid Dextrose Peptone Agar at $30^{\circ}$. 
Treatments. (a) Heat. Bacteria in $5 \mathrm{~cm}^{3}$ growth medium in a thin walled glass tube were placed in a water bath at $52^{\circ}$ for the required length of time. The temperature in the tube rose to within $0.5^{\circ}$ of the final temperature in $50 \mathrm{sec}$. (b) Radiation. Bacteria in $5 \mathrm{~cm} .{ }^{3}$ growth medium were chilled from o to $5^{\circ}$ to halt growth, which treatment produced no detectable loss of viability, and exposed to $\gamma$-radiation from two ${ }^{60} \mathrm{Co}$ sources at a dose rate of approximately $3.6 \mathrm{krad}$. min. ${ }^{-1}$. Air was bubbled through the suspension during irradiation.

Sedimentation of DNA. Spheroplasts were produced from Escherichia coli $\mathrm{B}_{3} \mathrm{r}$ Thy $^{-}$ which had been grown in glucose + salts medium in the presence of ${ }^{3} \mathrm{H}$-thymine and lysed on the top of a sucrose gradient at $\mathrm{pH}$ i2. The techniques described by McGrath \& Williams (I966) were followed closely. The $5 \mathrm{~cm} .{ }^{3}$ gradients were centrifuged at $30,000 \mathrm{rev} . \mathrm{min}$. in an M.S.E. Superspeed 65 ultracentrifuge for $90 \mathrm{~min}$. Tubes were pierced with an M.S.E. tube piercer and samples collected on to filter paper. The papers were washed twice in cold $5 \%$ trichloracetic acid, once in cold $95 \%$ ethanol, twice in cold acetone, and the activity counted in a Beckman scintillation counter.

\section{RESULTS}

\section{Sedimentation of heated DNA}

The alkaline sucrose sedimentation profile of DNA from Escherichia coli $\mathrm{B}_{3} \mathrm{r}$ which had been heated at $70^{\circ}$ for $20 \mathrm{~min}$. indicated that the average molecular weight was very considerably decreased compared with DNA from unheated bacteria, i.e. much strand breakage had occurred. The same effect was observed, although to a lesser degree, when bacteria were heated at $52^{\circ}$, only a few degrees above their maximum temperature for growth (Fig. I). Similar results were obtained with E. coli $\mathrm{B}_{8-1}$ Thy $^{-}$. The lowering of molecular weight produced by $20 \mathrm{~min}$. at $52^{\circ}$ was roughly the same as that produced by $20 \mathrm{krads}$. of $\gamma$-radiation. We therefore conclude that mild heating may directly or indirectly give rise to DNA strand breakage or alkali-labile sites.

\section{Correlation of heat and radiation sensitivities}

Figure 2 shows heat and radiation survival curves for strains $\mathrm{B} / \mathrm{r}$ and $\mathrm{B}_{\mathrm{B}-1}$ of Escherichia coli. Strain $\mathrm{B}_{\mathbf{b}-1}$ clearly has a greater sensitivity than $\mathrm{B} / \mathrm{r}$ to both mild heating and $\gamma$-radiation. A similar ordering of heating and radiation sensitivities was found (Fig. 3) with $E$. coli $\mathrm{H} / \mathrm{r}-30 \mathrm{R}$, which is resistant at the known radiation sensitivity loci, and two sensitive mutants, NG 30 which behaves as a 'reckless' $\mathrm{Rec}^{\text {' }}$ and $\mathrm{R}$ I 5 which behaves as a 'cautious' $\mathrm{Rec}^{-}$or possibly $\mathrm{Exr}^{-}$or Lex- (for a discussion of these terms see Howard-Flanders, 1968).

Values of LD 90 (dose or time to decreased initial viable population to $10 \%$ ) for heating at $52^{\circ}$ have been plotted against those for $\gamma$-irradiation for a number of strains (Fig. 4) and the correlation between the two is good. The point which lies most markedly off the general trend is that for $E$. coli B plated on nutrient agar and there is a ready explanation for this. The sensitivity to ionizing radiation of $\mathrm{B}$ relative to $\mathrm{B} / \mathrm{r}$ on rich media is due to an allele (lon) responsible for a defect in cell division probably caused by DNA synthesis becoming out of phase with RNA and protein synthesis (Alper \& Gillies, I958; Witkin, I966; Kantor \& Deering, I968). This sensitivity may be abolished by heating the bacteria to $45^{\circ}$ (Harm \& Stein, I952; Alper, 196I). Therefore, even if 
heating to $52^{\circ}$ caused damage to DNA, its effects on the cell division system would not be expressed and the resistance to heat would appear higher than expected. When $E$. coli в is plated on minimal agar where the defect in cell division is suppressed (Alper \& Gillies, 1960), the LD90 for mild heat has the expected value relative to that for radiation.

Occasionally the heat sensitivity of radiation sensitive strains was extreme, which accounts for the large variation about the mean in these cases.

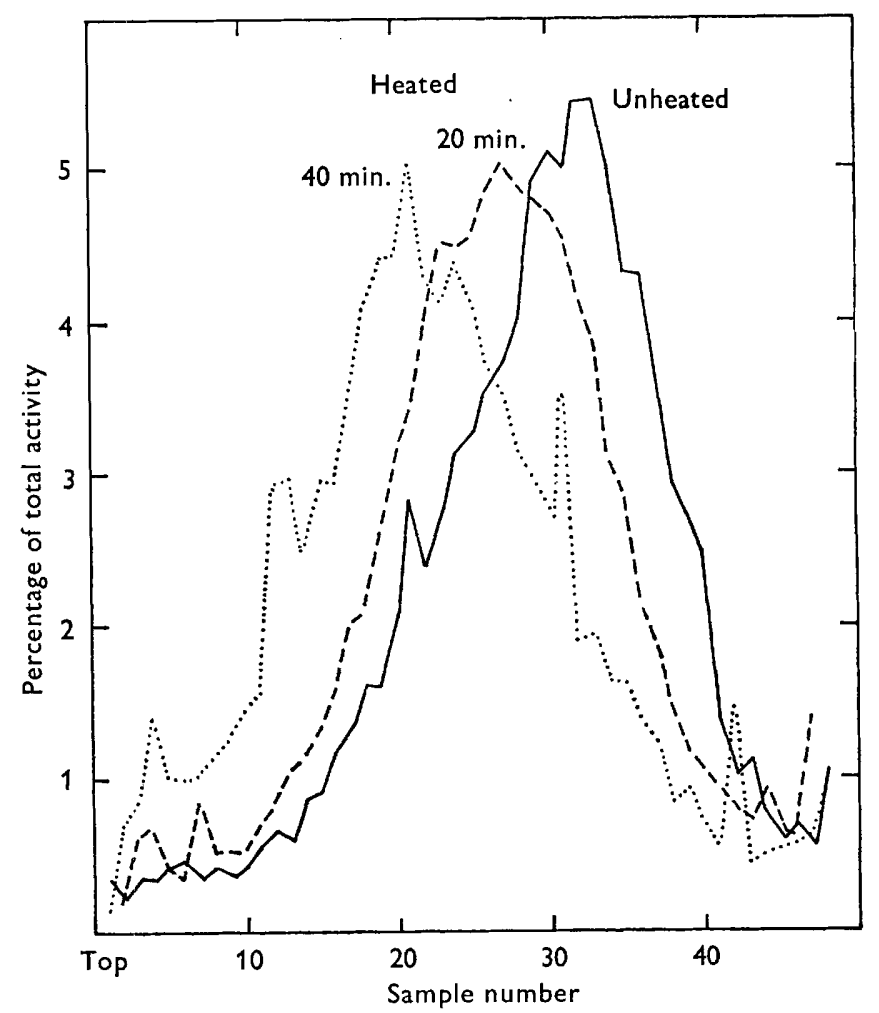

Fig. I. Sedimentation profiles in a sucrose gradient at $\mathrm{pH}$ i2 2 of ${ }^{3} \mathrm{H}$-thymine-labelled DNA from $E$. coli $\mathrm{B}_{3} \mathrm{r}$ heated for 0,20 and $40 \mathrm{~min}$. at $52^{\circ}$ and lysed on top of the gradient using the technique of McGrath \& Williams (1966). The means of the curves are $29 \cdot 2,26.6$ and $22 \cdot 9$, and the second moments about the means $78 \cdot 7,79 \cdot 8$ and 97.9 , respectively.

\section{Heat inactivation of recovery}

Examination of the survival curves in Fig. 2 and 3 reveals that the heat resistance of the resistant strains is in large measure due to the presence of a shoulder; at the longer heating times the slopes of the survival curves approach those of the sensitive strains. This suggests that the ability of a cell to repair or bypass thermal damage is itself sensitive to heating. This being so it would be expected that resistant bacteria surviving a heat treatment should be more sensitive to ionizing radiation. Figure 5 shows that the sensitivity of Escherichia coli $\mathrm{B} / \mathrm{r}$ to $\gamma$-radiation was increased by a factor of $2 \cdot 7$ after $15 \mathrm{~min}$. incubation at $52^{\circ}$ which decreased the viable fraction to about $7 \%$. The sensitive strain $B_{8-1}$ showed only a slight increase in sensitivity after a heat treatment 


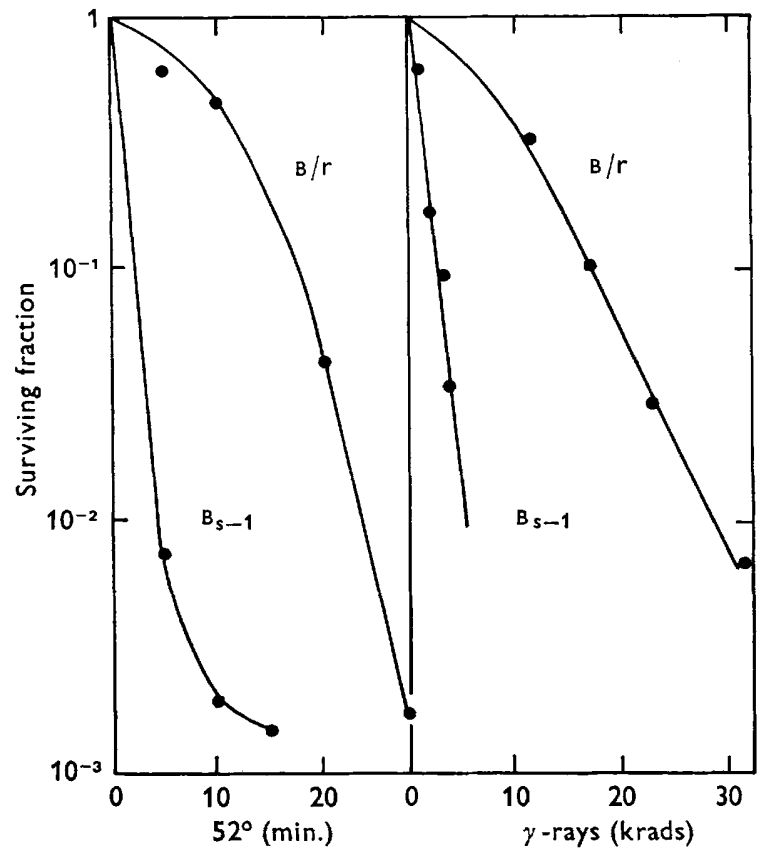

Fig. 2. Survival of $E$. coli $\mathrm{B} / \mathrm{r}$ and $\mathrm{B}_{\mathrm{a}-1}$ from exposure to $\gamma$-radiation under aerobic conditions, or to a temperature of $52^{\circ}$. Bacteria were grown in glucose + salts medium.

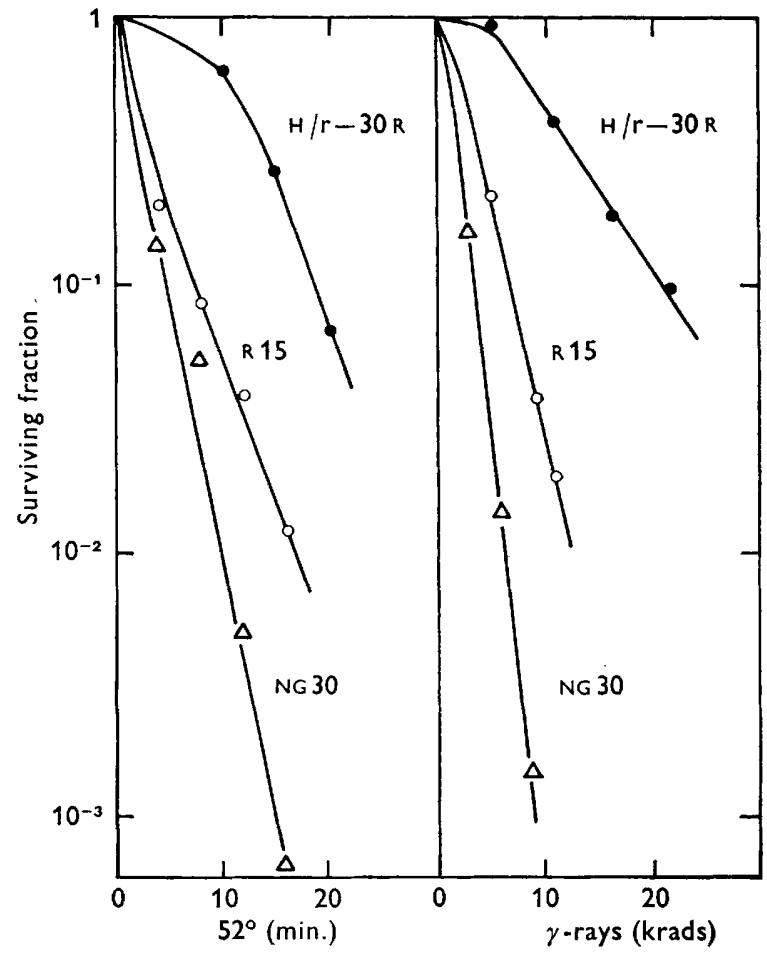

Fig. 3. Survival of $E$. coli $\mathrm{H} / \mathrm{r}-30 \mathrm{R}$ and two radiation-sensitive mutants $\mathrm{R}$ I 5 and NG 30 from exposure to $\gamma$-radiation under aerobic conditions, or to a temperature of $52^{\circ}$. Bacteria were grown in nutrient broth. 
which decreased the viability to a comparable extent. This interaction between heat and ionizing radiation resembles, at least superficially, that between u.v. and ionizing radiation studied by Haynes (1964).

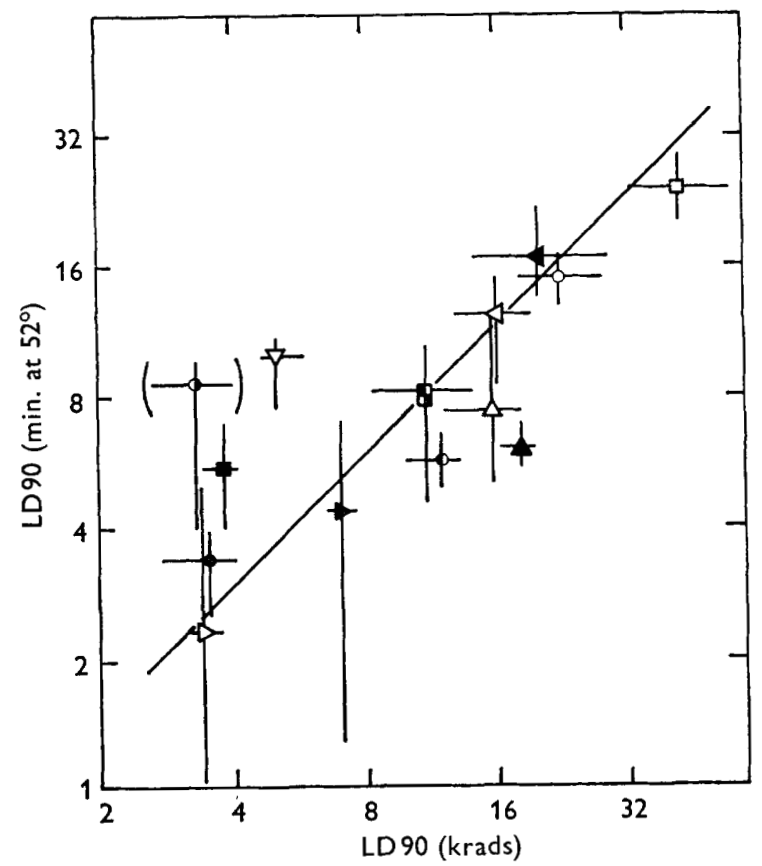

Fig. 4. Plot of sensitivity to a temperature of $52^{\circ}$ against sensitivity to $\gamma$-radiation of various strains of $E$. coli grown in nutrient broth: 0 , B/r; $\boldsymbol{C}$, B; $\boldsymbol{O}$, B on glucose-salts agar; $\bullet$,

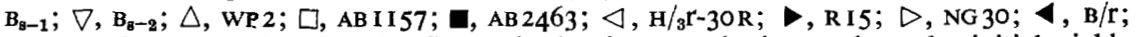
$\Delta$, WP 2 hor-; $\mathbf{D}$, IV $-5 ; \mathbf{U}, \mathrm{V}-5$. LD 90 is the dose required to reduce the initial viable population to $10 \%$ and is taken from three independent survival curves. The lines represent the range of experimental values.

\section{Involvement of known loci in heat sensitivity}

At the present time we know of several well defined phenotypes with regard to the response of Escherichia coli strains to ionizing and ultraviolet radiations (see, for example, Witkin, 1967; Howard-Flanders, I968) and many of the genetic loci involved have been mapped (e.g. Adler, I966).

The effect of known loci on heat sensitivity can be determined only by the comparison of pairs of strains which are believed to be otherwise isogenic, one having been derived from the other.

There are two pairs of strains differing in the 'reckless' Rec- phenotype: AB I I57 and $A B 2463$, and $H / r 30-R$ and NG 30. In both cases the $\mathrm{Rec}^{-}$phenotype confers extreme heat sensitivity.

The Exr- $^{-}$phenotype sometimes has an insignificant effect on radiation sensitivity ( $c f$. for example, VI-5 with V-5). Heat sensitivity is also identical in these strains. In combination with the Lon ${ }^{-}$and $\mathrm{Hcr}^{-}$phenotypes, however, $\mathrm{Exr}^{-}$may have a large

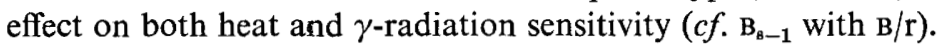

The Hor phenotype usually has a large effect on sensitivity to u.v. radiation 
(WP $2 \mathrm{Hcr}^{-}$is about 16 times more sensitive than WP 2) but has no effect on sensitivity to heat and ionizing radiation (as judged by comparing WP 2 and WP $2 \mathrm{Hcr}^{-}$) except possibly when combined with Lon $^{-}$and Exr $^{-}$(as in $\mathrm{B}_{\mathbf{s - 1}}$ ).

The Lon- phenotype increases sensitivity to both heat and ionizing radiation as may be seen by comparing $\mathrm{B}$ with its suppressed derivative $\mathrm{B} / \mathrm{r}$. This is manifest even though the expression of the Lon- phenotype itself is known to be partially inhibited by heating as mentioned above.

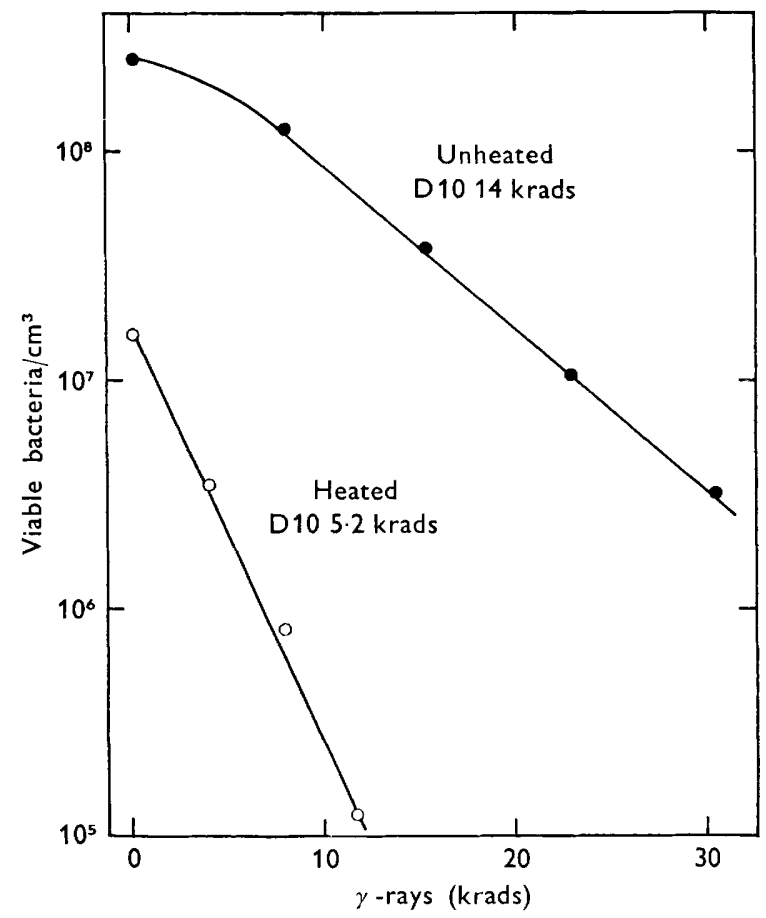

Fig. 5. Sensitivity to aerobic $\gamma$-radiation of $E$. coli $\mathrm{B} / \mathrm{r}$ with and without preliminary exposure to $52^{\circ}$ for $15 \mathrm{~min}$. Bacteria were grown in glucose-salts medium. D Io is the dose necessary to decrease the viable population by a factor of 10 on the straight portion of the curve.

\section{Extension of hypothesis to other organisms}

A further possibility that arises from our hypothesis is that organisms which grow well at high temperatures might be expected to show greater than average resistance to ionizing radiation. We have tested vegetative forms of several thermophilic strains of Bacillus stearothermophilus and obtained LD90 values of 40 to 50 krads when the incubation temperature was $52^{\circ}$, a temperature at which the recovery systems presumably have to cope with both thermal and radiation damage. They thus exhibit rather more resistance to $\gamma$-radiation than any of the Escherichia coli strains or nonthermophilic strains of Bacillus (Freeman \& Bridges, 1960). These thermophiles did not grow, however, at $37^{\circ}$ where thermal damage to DNA would be further decreased and where one might expect even greater resistance to ionizing radiation.

One cannot predict with any certainty that extremely radiation-resistant organisms should be heat-resistant since factors other than DNA damage, e.g. protein denatura- 
tion, are expected to be involved in heat inactivation and the importance of these factors will tend to be greater at longer heating times. It is nevertheless noteworthy that the extremely radiation resistant Micrococcus radiodurans with an LD 90 value of $68 \mathrm{~min}$ at $52^{\circ}$ is considerably more resistant to heat than our most resistant Escherichia coli strain (Fig. 6), and that the survival curve has the long shoulder typical of that exhibited to ultraviolet and X-radiation (Moseley \& Laser, I965).

Obviously much more information will be required before it is clear how general is the correlation we have shown for Escherichia coli.

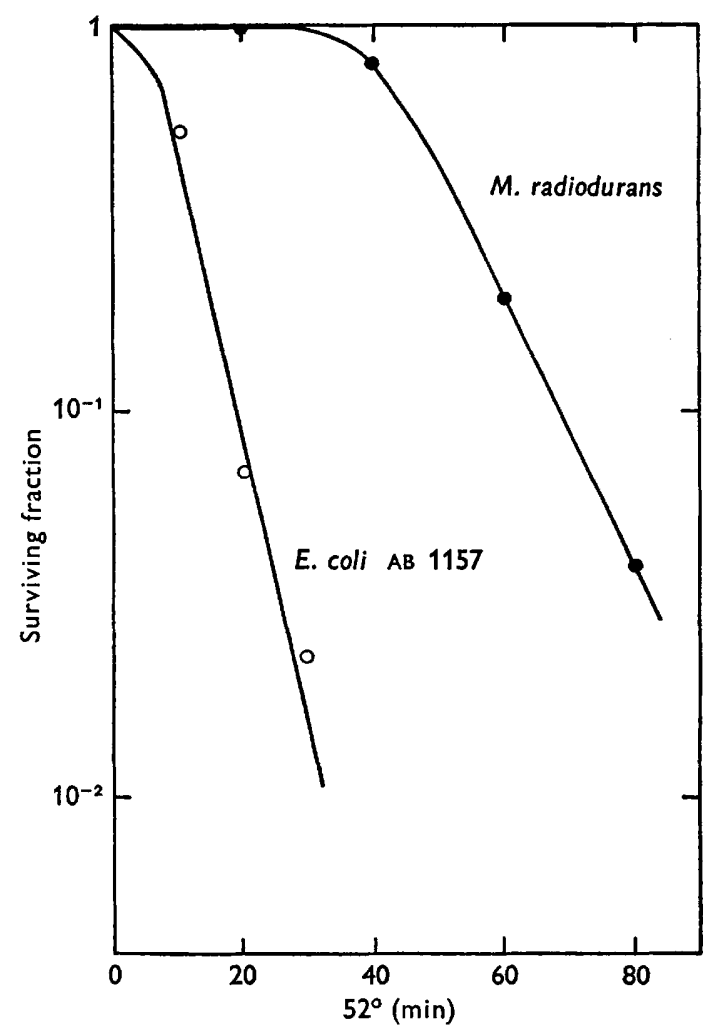

Fig. 6. Survival of Micrococcus radiodurans and $E$. coli $\mathrm{K} \mathrm{I} 2 \mathrm{AB} I \mathrm{I} 57$ grown in nutrient broth from exposure to a temperature of $52^{\circ}$.

\section{DISCUSSION}

Haynes (1964) previously examined the sensitivity to incubation at $60^{\circ}$ of three strains of Escherichia coli, $\mathrm{B} / \mathrm{r}, \mathrm{B}$ and $\mathrm{B}_{\mathrm{s}-1}$. All three strains were equally sensitive and Haynes was probably correct in assuming that death was due to generalized protein denaturation and enzyme destruction. Our present results show clearly that there is a general correlation between sensitivity to ionizing radiation and sensitivity to incubation at $52^{\circ}$ among various strains of $E$. coli, although the scatter around the line in Fig. 4 suggests that there are factors influencing heat sensitivity alone or radiation sensitivity alone. 
The correlation implies that, as far as the Escherichia coli cell is concerned, mild thermal damage and ionizing radiation damage appear very similar. There is strong evidence that inactivation by ionizing radiation is due to damage to the DNA (Haynes, I964; Moseley, 1968; Strauss, I968; Bridges \& Munson, 1968), so that it is a logical step to suppose that at $52^{\circ}$, in contrast to $60^{\circ}$, protein damage (at least at short heating times) is relatively unimportant and that the effective lethal damage is also located in the DNA.

Our results further imply that Escherichia coli bacteria use the same processes to repair or mitigate the effects of both types of damage. The fact that mild thermal stress is much more common in nature than ionizing radiation suggests that the repair and bypass systems may have evolved to cope with the former rather than the latter. However attractive this might be as an explanation, it must be pointed out that the ability of cells to cope with a certain amount of both types of damage may be merely a bonus conferred on the cell by systems whose real function is much more important, for example in effecting genetic recombination or in controlling cell and nuclear division. A similar suggestion has been made to explain the widespread occurrence of photoreactivating enzyme (Cook \& McGrath, 1967).

Among the strains we examined, every mutation affecting sensitivity to ionizing radiation also affected heat sensitivity, but a mutation $\left(\mathrm{hcr}^{-}\right)$which altered sensitivity to u.v. radiation by a factor of 16 or more, was without effect on heat or gamma ray sensitivity.

The ability of the more resistant bacteria to cope with mild thermal and gamma radiation damage is itself heat-sensitive. In this respect it is similar to the system involved in repair of X-ray and ultraviolet damage in yeast (Patrick \& Haynes, 1964).

Although our observation of the change in sedimentation pattern of bacterial DNA after heating prompted us to perform the biological experiments, we have not established that the thermal damage involved in inactivation is single-strand breakage of DNA. We have not, for example, been able to demonstrate any repair of thermal DNA damage during subsequent incubation of resistant bacteria as was done for X-ray damage by McGrath \& Williams (1966). Nevertheless, the correlation both of sensitivity and of DNA profile in the alkaline sucrose gradient is highly suggestive.

We acknowledge with thanks the technical assistance of Miss Rachel Dennis and Mr John Law.

\section{REFERENCES}

AdLER, H. I. (1966). The genetic control of radiation sensitivity in micro-organisms. In Advances in Radiation Biology. Ed. by L. G. Augenstein, K. Mason and M. R. Zelle, vol. 2. New York: Academic Press.

ALPER, T. (1961). Variability in the oxygen effect observed with micro-organisms. Part II Escherichia coli B. Int. J. Radiat. Biol. 3, 369 .

AlPER, T. \& Gillies, N. E. (I958). 'Restoration' of Escherichia coli strain B after irradiation: its dependence on suboptimal growth conditions. J. gen. Microbiol. 18, 461.

AlPER, T. \& Gillies, N. E. (I960). The relationship between growth and survival of Escherichia coli strain B and two resistant mutants. J. gen. Microbiol. 22, I 3 .

Bridges, B. A. \& Munson, R. J. (I968). Genetic radiation damage and its repair in Escherichia coli. In Current Topics in Radiation Research. Ed. by M. Ebert and A. Howard, vol. 4. Amsterdam: North Holland.

Cook, J. S. \& McGrath, J. R. (1967). Photoreactivating-enzyme activity in metazoa. Proc. natn. Acad. Sci. U.S.A. 58, 1359. 
Eigner, J., BOEDTKeR, H. \& Michaels, G. (I96I). The thermal degradation of nucleic acids. Biochim. biophys. Acta 51, I65.

Freeman, B. M. \& Bridges, B. A. (1960). Suitability of various plating media for counting bacteria after exposure to gamma radiation. Int. J. appl. Radiat. Isotopes $8,136$.

FreIFELDER, D. (1965). Mechanisms of inactivation of coliphage T 7 by X-rays. Proc. natn. Acad. Sci. U.S.A. 54, 128.

Greer, S. \& ZAMenhof, S. (1962). Studies on depurination of DNA by heat. J. molec. Biol. 4, I23.

HAAS, F. L. \& Doudney, C. O. (I957). A relation of nucleic acid synthesis to radiation-induced mutation frequency in bacteria. Proc. natn. Acad. Sci. U.S.A. 43, 871.

HAGEN, U. \& WeLlstein, H. (1965). Untersuchungen über die Strahlenempfindlichkeit der Desoxyribonukleinsäure. III. Brüche und Vernetzungen nach direkter Bestrahlung. Strahlentherapie 128, 565 .

HARM, W. \& SteIN, W. (1952). Vergleich der UV-Inaktivierung und Wärmeaktivierung von verschiedenen UV-empfindlichen Coli-Kulturen. Natürwissenschaften 39, 2 I 2.

HAYNES, R. H. (1964). Role of DNA repair mechanisms in microbial inactivation and recovery phenomena. Photochem. Photobiol. 3, 429.

HowARD-Flanders, P. (1968). DNA repair. A. Rev. Biochem. 37, 175.

Howard-Flanders, P. \& Theriot, L. (I966). Mutants of Escherichia coli K-I2 defective in DNA repair and in genetic recombination. Genetics, Princeton 53, II 37.

KantoR, G. J. \& DeERING, R. A. (1968). Effect of nalidixic acid and hydroxyurea on division ability of Escherichia coli fil ${ }^{+}$and lon $^{-}$strains. J. Bact. 95, 520.

MCGRath, R. A. \& Williams, R. W. (1966). Reconstruction in vivo of irradiated Escherichia coli deoxyribonycleic acid; the rejoining of broken pieces. Nature, Lond. 212, 534.

Moseley, B. E. B. (1968). The repair of damaged DNA in irradiated bacteria. In Advances in Microbial Physiology. Ed. by A. H. Rose and J. F. Wilkinson, vol. 2. London: Academic Press.

Moseley, B. E. B. \& LASER, H. (1965). Similarity of repair of ionizing and ultraviolet radiation damage in Micrococcus radiodurans. Nature, Lond. 206, 373.

Patrick, M. H. \& Haynes, R. H. (1964). Dark recovery phenomena in yeast. II. Conditions that modify the recovery process. Radiat. Res. 23,564 .

Strauss, B. A. (1968). DNA repair mechanisms and their relation to mutation and recombination. Current Topics in Microbiology and Immunology 44, I.

WitkIn, E. M. (I966). In discussion. Radiat. Res. Suppl. 6, 26.

WITKIN, E. M. (I967). Mutation-proof and mutation-prone modes of survival in derivatives of Escherichia coli B differing in sensitivity to ultraviolet light. Brookhaven Symp. Biol. 20 , 17. 